\title{
A influência do terceiro setor no Estado
}

\author{
The third sector's influence on the State
}

La influencia del tercer sector en el Estado

Vivian de Almeida Gregori Torres

- Doutora em Direito do Estado pela Faculdade de Direito da Universidade de São Paulo (FD-USP)

- Mestre em Direito Político e Econômico pela Universidade Presbiteriana Mackenzie (UPM)

- Especialista em Direito Empresarial pela UPM

- Graduada pela Faculdade de Direito de São Bernardo do Campo (FDSBC)

- Professora na Universidade Nove de Julho (Uninove)

- Coordenadora de Cursos de Extensão na Universidade Mogi das Cruzes (UMC)

- Presidente da Comissão de Pesquisa e Pós-Graduação em Direito da OAB/SP

- Fundadora e Diretora Financeira do Instituto Gregori Caggian

- E-mail: viviangregori13@gmail.com 


\section{Resumo}

Este trabalho estuda o papel e a atuação do terceiro setor em ambiente democrático, dando-se ênfase à ampliação da cidadania promovida pelo terceiro setor e o papel desempenhado no cenário político no sentido de instrumento de aprimoramento democrático. Demonstrar-se-á que a atuação do terceiro setor tem viabilizado uma participação política de melhor qualidade e com real possibilidade de ingerência no Estado, em atendimento aos anseios do cidadão que vive numa sociedade complexa, onde a democracia representativa não mais o atende.

\section{PALAVRAS-CHAVE: DEMOCRACIA • TERCEIRO SETOR・REPRESENTAÇÃO POLITICA.}

\section{Abstract}

This paper studies the role and performance of the third sector in a democratic environment, emphasizing the expansion of citizenship fostered by the third sector and the role played in the political scenario as an instrument for the improvement of democracy. This document will demonstrate that the activities of the third sector have enabled political participation with improved quality and with real possibility of intervention in the State, in response to the wishes of the citizens living in a complex society, which are no longer fulfilled by the representative democracy.

\section{KEYWORDS: DEMOCRACY • THIRD SECTOR・POLITICAL REPRESENTATION.}

\section{Resumen}

En este trabajo se estudia el papel y la actuación del tercer sector en un entorno democrático, dando énfasis a la expansión de la ciudadanía promovida por el tercer sector y el papel que desempeña en la arena política con el fin de mejorar el instrumento democrático. Se demostrará que la actuación del tercer sector ha permitido una participación política de mejor calidad y con una posibilidad real de interferencia en el Estado, de acuerdo con los deseos de los ciudadanos que viven en una sociedad compleja donde la democracia representativa ya no los atiende más. 
0 homem é um ser sociável que não se adapta bem ao isolamento. Por isso tende a viver em grupo pelos mais variados motivos, que permeiam desde a questão psicológica até a questão da sobrevivência. No entanto, a vida em comum exige organização e certo regramento para se tornar possível, fazendo surgir a sociedade civil, que na concepção de vários filósofos tem por evolução natural a instituição do Estado.

0 Estado, nesse contexto, tem por funções primordiais regular a convivência social e garantir direitos. Surge, assim, a necessidade de se organizarem as relações entre governantes e governados por meio de um regime político. Esse regime se constitui, em grande parte das nações, na democracia.

0 mundo moderno adotou a democracia representativa, na qual o povo elege os representantes que, ao final, serão a "personificação" do Estado. Contudo, a participação do povo no Estado não mais é atendida pelo mero depósito do voto nas urnas, visto que a sociedade quer uma atuação cidadã mais contundente.

A cidadania dos tempos atuais denota que, além de uma representação que entenda condigna, quer uma ampliação do espaço participativo. As lutas pelo direito ao voto, pelo sufrágio universal e pela legalização dos partidos são direitos conquistados que já fazem parte da essência do povo, considerados, portanto, "normais" e mínimos.

A sociedade clama agora por mais participação, não se contentando em simplesmente passar seu poder e esperar que seus representantes tudo façam; essa entrega plena da ação política e a submissão com relação às consequências da representação não mais atendem aos anseios políticos do povo, especialmente ante a crise da representatividade pela qual passa o Brasil.

A história é feita de ciclos e, nesse aspecto, a sociedade do século XXI quer reviver, em certa medida, a democracia direta dos atenienses. É claro que tal fato, ante as dimensões dos estados, a quantidade populacional e a complexidade da vida social moderna, é inviável. Contudo, o ser humano é criativo e adaptável, buscando sempre formas de atender seus anseios, e nesse cenário encontrou no terceiro setor um meio pacífico de ampliar sua participação de uma forma mais direta e incisiva.

0 terceiro setor tem o condão de servir de ferramenta para a sociedade civil organizar-se e mobilizar-se de tal forma a influir no Estado e, por consequência, nas políticas públicas adotadas. É a moderna participação política do cidadão.

Feitas essas considerações, o presente trabalho pretende analisar o papel e a atuação do terceiro setor em ambiente democrático. De igual modo, objetiva-se analisar a capacidade desse ator de influenciar no Estado.

Assim, num primeiro momento será estudada a democracia enquanto meio de exercício da cidadania e sua ampliação por intermédio do terceiro setor. Em seguida, será abordado o quanto o alargamento da cidadania fomentada pelo terceiro setor tem de poder para influenciar no Estado. 0 estudo será desenvolvido a partir, primordialmente, da revisão de literatura sobre o assunto e da situação política pela qual passa o Brasil. Deste modo, pretende-se apresentar elementos que demonstram que a nova democracia participativa é operada pelo terceiro setor, através de sua influência no Estado.

\section{DEMOCRACIA E TERCEIRO SETOR}

Como definição mínima de democracia, esta é entendida como um sistema político que assegura à população adulta (cidadãos) a oportunidade de participar das decisões políticas que dizem respeito ao polo dos decision makers. 
O significado clássico de cidadania está associado à participação política. É notoriamente um termo relacionado com a vida em sociedade. Sua origem está ligada ao desenvolvimento da pólis grega, entre os séculos VIII e VII a.C. A partir de então, esse desenvolvimento tornou-se referência para os estudos que enfocam a política e as próprias condições de seu exercício, tanto nas sociedades antigas quanto nas modernas. Por outro lado, as mudanças nas estruturas socioeconômicas incidiram, igualmente, na evolução do conceito e da prática da cidadania, moldando-a de acordo com as necessidades de cada época.

A democracia é uma forma de governo que apresenta solo fecundo para o exercício da cidadania; ela é desejável porque concede espaço para o homem ser e existir, comandando as ações responsáveis por seu próprio futuro.

0 modelo de democracia vivido atualmente é a indireta, cuja pedra fundamental é a representação. 0 voto é a legítima expressão da vontade do povo, meio pelo qual este exerce a cidadania escolhendo quem melhor representa seus interesses; é uma forma de participação na decisão política' e condução da coisa pública².

O representante será definido com o auxílio dos partidos políticos e pelo voto. A questão reside no fato de que o voto sem consciência e impensado, feito de forma irresponsável, conduz à desorganização política, que é agravada pelos partidos no caso brasileiro, em razão de estarem enfraquecidos, homogeneizados, sem direcionamento e descomprometidos com um programa de governo. Os dois fatos somados resultam em um cenário no qual o cidadão acaba elegendo um representante que nada representa.

No caso brasileiro, com a deterioração da qualidade do político, que busca a eleição apenas para conjugar seus interesses ao interesse do Estado e, com isso, se locupletar o máximo possível, não se pode afirmar com exatidão que o atual modelo de democracia representativa garante a participação do povo na decisão política. Os brasileiros estão indo para as ruas, fazendo protestos, tentando tomar para si, de volta, a decisão política. É uma releitura moderna da democracia ateniense feita na praça pública.

Nesse sentido, os movimentos sociais e o terceiro setor têm o condão de servir de ferramenta para a sociedade civil organizar-se e mobilizar-se de tal forma a influir no Estado e, por consequência, nas políticas públicas adotadas. É a moderna participação política do cidadão. ${ }^{3}$

\section{TERCEIRO SETOR E CIDADANIA}

Para tratar do tema da cidadania, é importante discutir a participação dos cidadãos na res publica. Sob este aspecto trazse à luz o pensamento de Benjamin Constant sobre a "liberdade dos antigos" e a "liberdade dos modernos" - a primeira traduzia a exigência e garantia de participação nas decisões políticas e a outra correspondia à distinção perante o poder, sendo vedada a ingerência deste sobre o indivíduo. A "liberdade dos modernos" reclama um Estado de direito, enquanto que a "liberdade dos antigos" postula um Estado democrático4.

\footnotetext{
1 "O voto em sua simplicidade, exprime com segurança uma escolha política concreta e não mera opinião abstrata" (Lembo, 1991, p. 53).

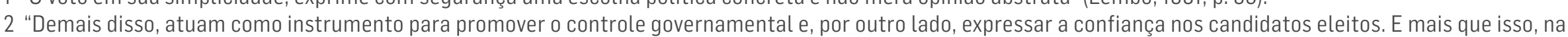

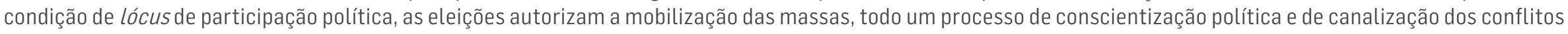
mediante procedimentos pacíficos. Contribuem, ainda, para a formação da vontade comum" (Caggiano, 2004, p. 74).

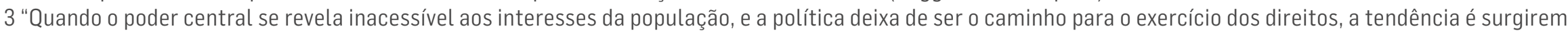

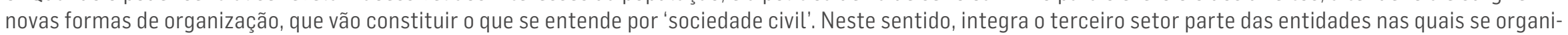
zam os membros da sociedade civil" (Naves, 2013, p. 546/547).

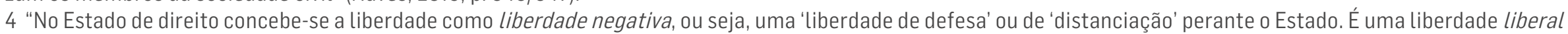

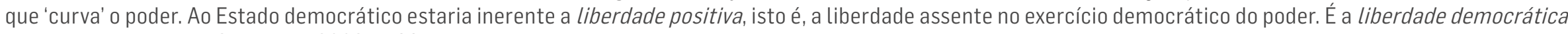
que legitima o poder" (Canotilho, 2003, p. 99).
} 
O Estado que a sociedade moderna almeja não pode limitar-se ao Estado de direito, devendo estruturar-se também como Estado de direito democrático ${ }^{5}$. Em termos de democracia, a experiência mais célebre foi a vivida pelos "antigos", que era direta, onde os próprios cidadãos exerciam o poder político. Nos estados modernos, tal forma democrática não se faz mais possíve $l^{6}$, tratando-se de uma democracia representativa e indireta na qual a participação do cidadão se faz mais relevante no momento em que elege seus representantes, exerce seu direito ao voto e participa das eleições?

Todavia, a democracia representativa passa a corresponder ao processo de eleição dos representantes pelos representados, sendo a forma de participação política restringida ao âmbito da consulta eleitoral, restando ao representado, caso não se sinta devidamente atendido quanto às suas expectativas, tão somente não reeleger seu representante ${ }^{8}$. Nessa perspectiva, a participação política é, em certa medida, "mediocrizada" e reduzida ao pleito eleitoral.

Sob esse prisma, acertadamente a professora Monica Herman Salem Caggiano assevera que o eleitor "pretende mais do que depositar o seu voto na urna" (Caggiano, 2013, p. 267), ele participa ativamente antes, durante e posteriormente ao pleito eleitoral, exigindo integridade e honradez nas eleições, utilizando os meios modernos de comunicação para debater os candidatos e as propostas veiculadas e, "consciente de sua relevância na produção da decisão política, o eleitor exerce a cidadania por intermédio de todos os instrumentos que o novo constitucionalismo e a sofisticada tecnologia colocou à sua disposição" (Caggiano, 2013, p. 268); emprega o uso de mecanismos legais, tais como: a ação popular; 0 mandado de injunção; o mandado de segurança coletivo; a ação direta de inconstitucionalidade e a iniciativa popular. E, mais, o cidadão passou a reconhecer, na busca do alargamento participativo, além dos instrumentos jurídicos, o terceiro setor como meio eficaz de influir no lócus governamental. Isso porque o terceiro setor traz a nuance de participação política de forma mais "direta" e concreta, não só influenciando nas decisões políticas como também auxiliando na implantação e identificação dessas políticas, figurando como canal de comunicação entre governantes e governados, contribuindo na formação da opinião pública, fiscalizando o governo e exigindo a implantação de políticas públicas.

0 terceiro setor oferece uma forma de a sociedade se organizar para exercitar a cidadania. Segundo Bernardo Toro, "0 Estado não é o salvador da pátria e que, quando a população se organiza, o país se torna mais livre, desenvolvido e inovador" (Toro, 2015, p.13). As ações constantes no tempo são as que surtem efeito e são fruto de sociedades verdadeiramente organizadas. A sociedade deve tomar a responsabilidade e articular-se de forma a mudar a ordem das coisas, deve agir mais do que reivindicar ou esperar que o Estado traga as soluções - um Estado superprotetor é terreno perfeito para o populismo autoritário e o clientelismo institucional, muito comum na América Latina.

Para Toro, as sociedades pouco organizadas e muito dependentes do Estado são as menos desenvolvidas, livres, democráticas, educadas e inovadoras. Nestes casos, a razão pelo fracasso é sempre exterior. Estes países tendem a ser corruptos pois dispõem de menos mecanismos de vigilância e cobrança sobre a classe política e o próprio Estado. A desorganização da sociedade, ao final, é seu grande indicador de pobreza. 0 autor afirma ainda que as sociedades organizadas, especialmente as constituídas por várias formas de organizações (terceiro setor), são mais exigentes e vigilantes, e é isto que faz com que as engrenagens de um país funcionem melhor, tornando-o mais produtivo e próspero (Toro, 2015, p. 13-17).

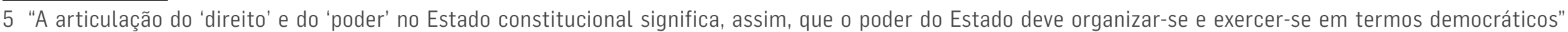
(Canotilho, 2003, p. 98).

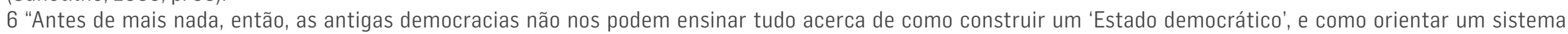

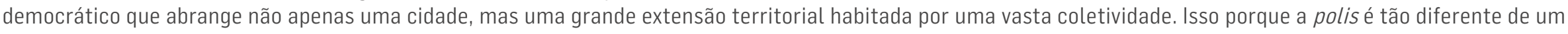
estado territorial como um rio de um oceano" (Sartori, 1965, p. 267).

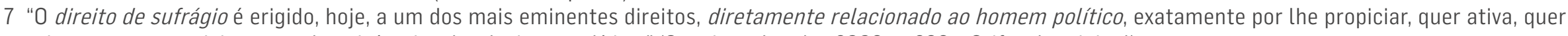
passivamente, a participar no polo epicêntrico das decisões políticas" (Caggiano; Lembo, 2009, p. 299 - Grifos do original).

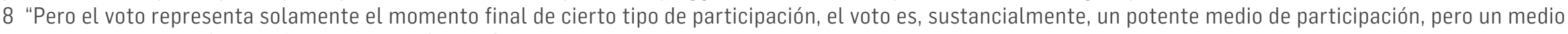
que transmite poca información" (Pasquino, 1974, p. 67).
} 


\section{O PAPEL DO TERCEIRO SETOR NA FORMAÇÃO DA CIDADANIA POLÍTICA}

A cidadania política do século XXI vai além do exercício do sufrágio. A participação inclui "os processos por meio dos quais os cidadãos influem ou controlam aqueles que tomam as decisões mais importantes que os afetam" (Pasquino, 1974, p. 67). É uma atividade complexa que suplanta a mera participação eleitoral, requer qualidades culturais e intelectuais ${ }^{9}$, constituindo a educação $0^{10}$, por consequência, uma das variáveis mais importantes para a efetivação da cidadania política". No que diz respeito à educação, Bernardo Toro assegura que ela é uma questão estratégica para o desenvolvimento de um país - a sociedade deve ser ancorada no conhecimento, pois quem possui instrução tem maiores aspirações na vida (Toro, 2015, p. 11).

Com relação ao assunto, Manoel G. Ferreira Filho afirma que o êxito de uma forma de governo depende muito mais da formação política e dos valores infundidos pela educação recebidas pelo povo do que das instituições jurídicas definidas constitucionalmente. 0 povo deve ser formado para a democracia, nele devem ser disseminados os valores democráticos de apego à liberdade e à igualdade, a dedicação ao interesse geral e o espírito cívico que a democracia reclama (Ferreira Filho, 1977, p.73).

Sob o aspecto educacional o Brasil figura entre os piores do mundo. 0 ensino proporcionado pelo Estado é de baixa qualidade e insuficiente em termos quantitativos e de distribuição no território nacional. Essa lacuna educacional atinge diretamente a qualidade participativa do cidadão, gera desmotivação e apatia política, uma vez que sem instrução específica não se compreendem as questões relacionadas aos negócios públicos e os interesses envolvidos no jogo político.

Apesar de a educação no Brasil ser um direito constitucionalmente garantido e um dever do Estado, ela é ineficiente e insuficiente. Nesse ponto o terceiro setor em muito pode e tem contribuído para preencher o hiato deixado pelo Estado ${ }^{12}$. Existem inúmeras entidades voltadas à educação e à informação, não só em termos do ensino formal (escolar), mas também em termos do ensino informal (reciclagem do trabalhador, formação política), com vistas a contribuir com a educação, aprimorar e incentivar a participação política e a cidadania ${ }^{13}$.

Aliado à questão educacional, outro aspecto com que o terceiro setor vem a contribuir com a cidadania política diz respeito à crise de representatividade, especialmente atribuída aos partidos políticos de cujos quadros saem os governantes e parlamentares. Existe uma crise de confiança da população em relação àqueles que conduzem o Estado, muito pelo fato de a "coisa pública" ser tratada como "coisa particular" por parte dos grupos que detêm o poder - em detrimento da população, os interesses particulares são sobrepostos aos interesses coletivos.

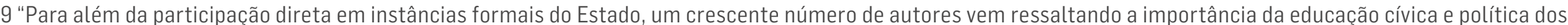

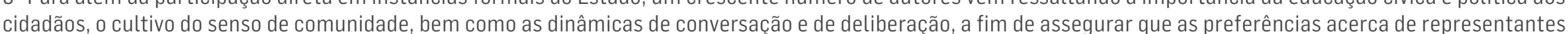

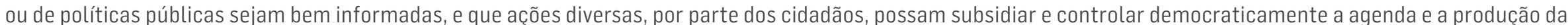
decisão política" (Maia, 2008, p. 327-328)

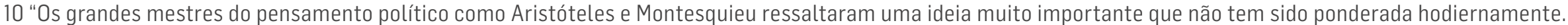

Tal ideia pode ser resumida na afirmação de que toda forma de governo presume uma determinada educação do povo" (Ferreira Filho, 1977, p. 73)

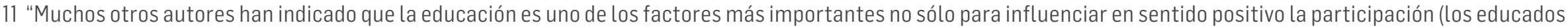
participan más que los no educados), sino también para alejar las posturas extremistas" (Pasquino, 1974, p. 68).

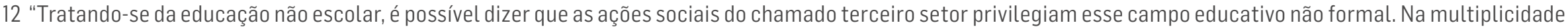
de suas práticas, o 'terceiro setor' tem investido na intervenção social via ação educativa" (Martins, 2010, p. 129)

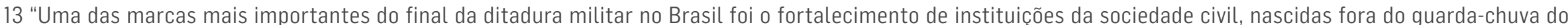

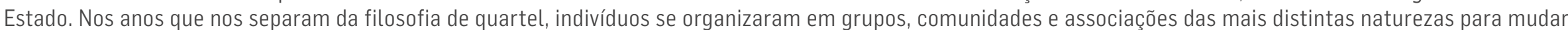

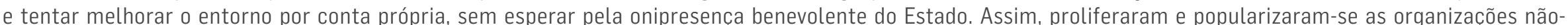

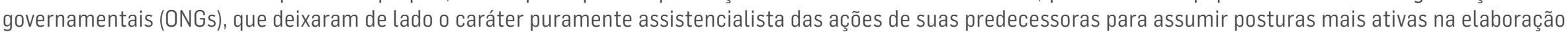

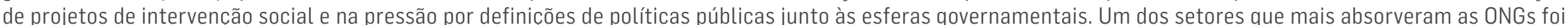

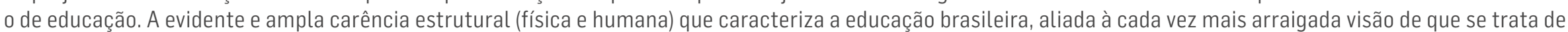

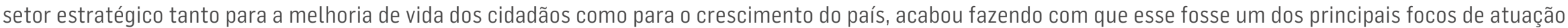
do terceiro setor, para o qual se volta com arco bastante amplo e heterogêneo de trabalhos em escolas e comunidades" (Curi, 2011) 
A organização da sociedade civil em instituições fora do aparelho estatal resulta numa forma participativa da cidadania. Por meio do terceiro setor, a sociedade passa a fiscalizar as atividades dos governantes e parlamentares, exige transparência e responsabilidade na condução da coisa pública, bem como encontra um meio de interface entre governantes e governados de forma que as suas reivindicações sejam ouvidas e atendidas.

Ainda sob o tema da crise de representatividade, o modelo democrático adotado pelo Brasil é o da representação articulada pelos partidos políticos, no qual estes realizam a interface entre o Estado e a sociedade, bem como definem os que poderão concorrer a um cargo representativo. Assim, a percepção de "sentir-se representado" está atrelada à proximidade dos cidadãos com os partidos e à funcionalidade destes. Contudo, o que se verifica é o distanciamento entre os cidadãos e os partidos. A insatisfação com a política partidária, e a precariedade no desempenho da função mediadora que os partidos deveriam executar, faz com que a sociedade não se sinta mais representada pelos partidos.

Os cidadãos passam a buscar, então, as entidades do terceiro setor para preencher a lacuna representativa deixada pelas agremiações partidárias, tendo em vista que o terceiro setor é composto de várias entidades com conhecimento e vínculo específico com determinados setores sociais, tais como: jovens, negros, mulheres ou a temas como as questões ambientais, o que o torna uma forma de representação desses grupos, expressando interesses difusos da sociedade junto ao Estado. Aliado a este fato, observa-se que o terceiro setor ainda está apto a defender causas impopulares ou enfrentar questões mal compreendidas, papel que, no geral, os partidos não querem desempenhar, com o claro intuito de não desagradar e sempre agregar simpatizantes.

0 terceiro setor também contribui com a formação da cidadania política, pois conscientiza as pessoas de que não basta protestar ou exigir atendimento aos interesses sociais, mas que é preciso colaborar e participar das políticas públicas a serem implementadas. Nessa dimensão têm-se as entidades voltadas para as questões de interesse público, capazes de formular projetos, monitorar sua execução e prestar contas não só financeiramente, mas também com relação às metas propostas. 0 terceiro setor tem o papel de ator complementar ao Estado na execução das políticas públicas e no engajamento da sociedade na concretização dessas políticas.

Esse comprometimento da sociedade com a cidadania participativa fez despertar também no meio empresarial o interesse em contribuir. Ao perceber que a responsabilidade social valorizava a suas marcas, as organizações passaram então a desenvolver projetos juntamente com entidades do terceiro setor que buscassem minimizar danos às comunidades do entorno de suas sedes e ao meio ambiente, surgindo um novo modo de fazer negócios menos agressivo do que o proposto pelo modelo liberal, tal como o das empresas que estimulam a produção artesanal e o desenvolvimento sustentável ${ }^{14}$, sendo a empresa Natura um exemplo a ser citado, que por meio de seu instituto cultural apoia e promove ações no âmbito educacional e ambiental.

Retornando à questão da formação política, destaca-se a democracia como uma forma de governo que deve ser cultivada. Como anteriormente mencionado no ensinamento de Manoel G. Ferreira Filho, a construção democrática não é dada ou imposta, mas é feita de conflitos e tensões permanentes, sendo que a atual democracia representativa padece de excesso de demandas das quais não tem dado conta ante uma sociedade complexa, heterogênea, repleta de direitos e interesses difusos e coletivos, não só nacionais como internacionais.

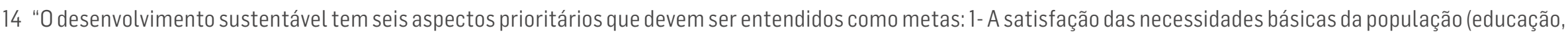

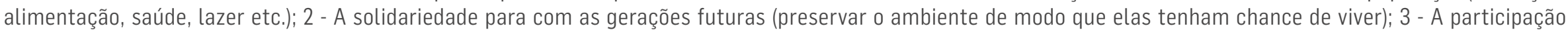

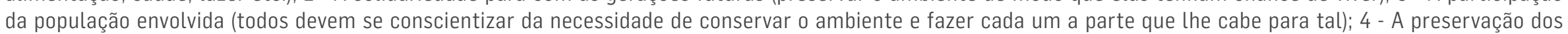

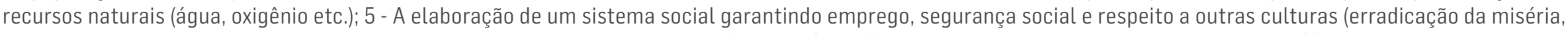
do preconceito e do massacre de populações oprimidas, como por exemplo os índios); e 6 - A efetivação dos programas educativos" (Mendes, 2015). 
Diante desse cenário de ineficiência da democracia representativa, novas formas de participação, que não seja pela mera participação eleitoral, tornaram-senecessárias. Sob este prisma, o terceiro setor podeampliar o espaço de atuação democrática ${ }^{15}$, funcionando como agente da democracia participativa, atuando, por um lado, na contensão de conflitos e tensões ${ }^{16}$ e, por outro, agindo diretamente no atendimento das demandas sociais ${ }^{17}$, além de funcionar no auxílio do Estado na definição e planificação das políticas públicas ${ }^{18}$ normalmente em razão das competências que possuem em sua área de atuação $0^{19}$.

Assim, à medida que o terceiro setor fomenta intervenções sociais democráticas, cria cidadania e autonomia (Toro, 2005, p. 116). Ainda sob o tema democracia, um mal que pode vir a solapar seus alicerces é a questão da corrupção, que nos últimos anos se alastrou na política de forma endêmica. 0 efetivo exercício da cidadania política não se resume à escolha dos governantes pelo voto, levando-se em conta as qualidades do candidato e seu programa de atuação; deve ir além, ser praticada antes, durante e depois das eleições. A cidadania inclui fiscalização do processo eleitoral e dos eleitos com o intuito de dificultar a prática da corrupção.

Nesse ponto, iniciativas do terceiro setor vieram a colaborar com o incremento da cidadania política na busca de tolher a corrupção, tal como a instituída pela entidade Transparência Brasil, que trabalha dados e os sistematiza em programas de fácil acesso e linguagem clara, promovendo estudos e informações públicas com o intuito de combater a corrupção.

Assim, fica evidente o papel do terceiro setor na formação da cidadania política. Por intermédio de suas entidades, ele organiza a sociedade civil e fornece ferramentas para que os indivíduos exerçam a cidadania na sua plenitude. Isso porque: incrementam a educação, incentivando, com isso, a participação política; informam o eleitor com o intento de auxiliar em melhores escolhas eleitorais; promovem a representação dos interesses dos vários grupos sociais junto ao Estado; favorecem a interface entre governantes e governados, fazendo com que o cidadão ganhe voz; cooperam com a definição e implantação de políticas públicas, abrindo espaço para que o cidadão não só influa diretamente no lócus governamental, mas também tenha a oportunidade de participar diretamente na execução de tais políticas; auxiliam na fiscalização das atividades do Estado fornecendo meios para que o cidadão exija transparência e responsabilidade na condução da coisa pública e, com isso, promovem também o combate à corrupção.

Todo esse complexo aparato de ações promovidas pelo terceiro setor no sentido de incrementar a cidadania política acaba, por consequência, levando-o, ao final, a influenciar no Estado.

\section{CONSIDERAÇÕES FINAIS}

Nas democracias da atualidade, a relação entre a sociedade e o governo se consubstancia com a eleição de representantes, ou seja, a forma de o cidadão influenciar/participar no Estado é por meio de seus representantes, por intermédio dos quais a sociedade sinaliza as políticas desejadas e responsabiliza os governantes pelas ações praticadas e pelos resultados obtidos e/ou percebidos.

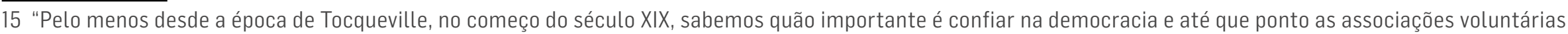
contribuem decisivamente para preservá-la" (Salamon, 2005, p. 98).

16 Atuação da OAB em defesa dos direitos da população e dos perseguidos politicamente no período da ditadura militar no Brasil.

17 Serviços prestados por instituições como Apae, Fundação Itaú, Fundação Bradesco, Unicef, Rotary Club etc.

18 Participação em audiências públicas e conselhos gestores.

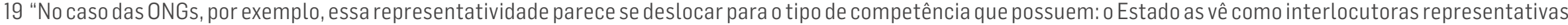
na medida em que detêm um conhecimento específico que provém do seu vínculo (passado ou presente) com determinados setores sociais" (Dagnino, 2002, p. 156). 
Contudo, a sociedade moderna clama por mais participação, surgindo, assim, diuturnamente, novas formas participativas que buscam ampliar o espaço democrático da vida política a partir de uma visão crítica do sistema representativo e da procura de uma maior eficiência econômica e social do uso dos recursos públicos. Essas novas faces participativas proporcionam o alargamento da educação política e do exercício da cidadania, além de auxiliar no controle do cumprimento dos compromissos feitos pelos governantes e de identificar e captar a necessidade de novas políticas públicas.

Nessa busca de novas formas participativas, a sociedade identificou o terceiro setor como instrumento capaz de oportunizálas, e ele passou a influenciar no Estado por "delegação" da sociedade, além de o terceiro setor ter tomado contornos de apoio institucional, auxiliando na interface entre a sociedade e o lócus governamental, atuando como intermediário entre estes.

Sob essa perspectiva, a sociedade passou a se organizar e representar por meio do terceiro setor, para exigir do Estado seus deveres e se responsabilizar e promover soluções para seus próprios problemas, restringindo a atuação do Estado apenas à equalização das situações.

O terceiro setor atua tanto na organização da sociedade quanto na promoção das soluções de seus problemas e, sob o prisma de um Estado social, adotado pelo Brasil nos últimos anos, o terceiro setor também desempenha um importante papel à medida que o Estado agigantado não se vê capaz de cumprir todos os seus deveres. Neste cenário, as entidades do terceiro setor preenchem as lacunas de atendimento deixadas pelo Estado, minimizando assim o impacto das massas descontentes e ampliando 0 atendimento das necessidades da população em um trabalho complementar ao Estado. Enfim, o terceiro setor passa a constituir um moderno instrumento da democracia que faz com que a cidadania tenha a possibilidade de ser exercida na sua plenitude.

0 poder do terceiro setor de influenciar no Estado é um fato que, no Brasil, decorre até mesmo por determinação constitucional, diante da criação de conselhos gestores no âmbito governamental, nos quais o terceiro setor tem ampla participação. Esta participação e influência possui grande importância para o processo de formulação de políticas públicas, ao passo que confere controle social ao poder e legitima as decisões governamentais. Essa participação social é desejável tanto para o aperfeiçoamento da democracia quanto para qualificar as políticas públicas.

0 terceiro setor se apresenta como verdadeiro instrumento democrático, tendo sua atuação especial lugar no controle do poder político e na implementação de políticas públicas. Ele tem o condão de servir de ferramenta para a sociedade civil organizar-se e mobilizar-se de tal forma a influir no Estado e, por consequência, nas políticas públicas adotadas, transmutando-se na moderna participação política do cidadão nas democracias atuais.

\section{REFERÊNCIAS}

CAGGIANO, Monica Herman Salem. O cidadão-eleitor, jogador com veto no processo eleitoral democrático. In: INSTITUTO VICTOR NUNES LEAL (Org.). A contemporaneidade do pensamento de Victor Nunes Leal. Instituto Victor Nunes Leal, organização. São Paulo: Saraiva, 2013.

Direito parlamentar e direito eleitoral. Barueri, SP: Manole, 2004.

; LEMBO, Cláudio Salvador. Dos direitos políticos. In: TANAKA, Sônia Yuriko Kanashiro (Coord.). Direito constitucional. São Paulo: Malheiros Editores, 2009. 
ANO 14 • NÚMERO 26 • 1은. 2017 - ORGANICOM

A INFLUÊNCIA DO TERCEIRO SETOR NO ESTADO

\section{3}

CANOTILHO, José Joaquim Gomes. Direito constitucional e teoria da constituição. Coimbra: Almedina, 2003.

CURI, Fabiano. A sociedade vai a escola. Revista Educação, Uol, ago. 2011. Disponível em: <http://revistaeducacao.uol.com. br/textos/154/artigo234713-1.asp>. Acesso em: 7 jan. 2016.

DAGNINO, Evelina. Democracia: teoria e prática. Rio de Janeiro: Relume Dumará; Curitiba: Fundação Araucária, 2002.

FERREIRA FILHO, Manoel Gonçalves. Sete vezes democracia. São Paulo: Convívio, 1977.

LEMBO, Claudio. Participação política e assistência simples no direito eleitoral. Rio de Janeiro: Forense Universitária, 1991.

MAIA, Rousiley C. M. Redes cívicas e internet: efeitos democráticos do associativismo. In: GOMES, Wilson; MAIA, Rousiley C.M. Comunicação e democracia: problemas \& perspectivas. São Paulo: Paulus, 2008.

MARTINS, Marcos Francisco; GROPPO, Luís Antonio. Sociedade civil e educação: fundamentos e tramas. Campinas, SP: Autores Associados; Americana, SP: Unisal, 2010.

MENDES, Marina Ceccato. Desenvolvimento sustentável. [Material de apoio - textos]. 2008. Disponível em: <http://educar. sc.usp.br/biologia/textos/m_a_txt2.html>. Acesso em: 7 jan. 2016.

NAVES, Rubens. Novas possibilidades para o exercício da cidadania. In: PINSKY, Jaime; PINSKY, Carla Bessanezi (Orgs.). História da cidadania. 6. ed. São Paulo: Contexto, 2013.

PASQUINO, Gianfranco. Modernización y desarrollo político.Barcelona: Nova Terra, 1974.

SALAMON, Lester. Estratégias para o fortalecimento do terceiro setor. In: IOSCHPE. Evelyn Berg (Org.). 3ํㅗ setor: desenvolvimento social sustentado. Rio de Janeiro: Paz e Terra, 2005.

SARTORI, Giovanni. Teoria democrática. Rio de Janeiro: Fundo de Cultura, 1965.

TORO, José Bernardo. O papel do terceiro setor em sociedades de baixa participação (quatro teses para discussão). In: IOSCHPE. Evelyn Berg (Org.). 3ํㅗ setor: desenvolvimento social sustentado. Rio de Janeiro: Paz e Terra, 2005.

. A sociedade precisa exigir. Veja, ed. 2.452, a. 48, n. 46, São Paulo, Editora Abril, 2015.

Texto recebido em 01.05.2017 e aprovado em 10.05.2017. 